Check for updates

Cite this: RSC Adv., 2018, 8, 11157

\title{
Authentication of pork in meat mixtures using PRM mass spectrometry of myosin peptides
}

\author{
Xiao-Dong Pan, (D) Jiang Chen, (D) * Qing Chen, ${ }^{*}$ Bai-Fen Huang and Jian-Long Han \\ Adulteration of meat products is a major concern not only for economic fraud, but also for ethical reasons. \\ In this study, we presented a parallel reaction monitoring (PRM) mass spectrometry approach for detection \\ of trace pork in meat mixtures (chicken, sheep, and beef). Specific peptides were identified and screened by \\ a shotgun proteomic approach based on tryptic digests of certain protein. Five surrogate peptides from \\ myosin were screened and then used for pork detection by PRM of Orbitrap MS. When the most \\ sensitive peptide was selected, the LOD in mixed meat can be up to $0.5 \%$. The RSD values between \\ detected and designated pork levels $(1 \%, 5 \%$ and $50 \%)$ were $4-15 \%$. The targeted method developed can \\ be applied to identify and quantify the pork in meat mixture.
}

Received 30th January 2018

Accepted 12th March 2018

DOI: $10.1039 / \mathrm{c} 8 \mathrm{ra00926k}$

rsc.li/rsc-advances electrochemical immunosensor, stable isotope ratio (SIR) analysis, NMR spectroscopy, and mass spectrometry based proteomics approaches..$^{5-7}$ Mass spectrometry (MS)-based proteomics methods only quite recently entered the field of food authentication. Specific proteins or peptides can be used as markers for many properties of a food.

Application of mass spectrometry methods to meat authentication has been described recently in the literature. ${ }^{5}$ Our previous study has proved that MS methods (Q-TOF-MS) can authenticate shrimp in fish balls by two specific heat stable peptides from tropomyosin and arginine kinase. ${ }^{8}$ Multiple reaction monitoring (MRM) mass spectrometric method was developed by Watson et al. for identification of four kinds of meat (beef, lamb, pork and horse) and detection of one meat added to another at levels of $1 \%(\mathrm{w} / \mathrm{w}) .{ }^{9}$ Orduna et al. identified proteotypic myoglobin tryptic peptides and characterized meat species by the specific extracted ion chromatograms of Q-Orbitrap MS. ${ }^{10}$ Four marker peptides for processed pork meat were identified by Sarah et al. who developed MRM methods for their detection. ${ }^{11}$ Claydon et al. constructed a database of heat stable unique tryptic peptides for nine meat species, which could detect down to $0.5 \%$ cooked and raw horse in a meat mixture. ${ }^{12}$ Ohana et al. used spectral libraries of tryptic peptides to screen 26 different mammalian and bird meats both in raw and processed foods. ${ }^{13}$

However, most of above methods used the MRM or selected reaction monitoring (SRM) for targeted peptides monitoring. Actually, high resolution mass spectrometry, for example Q-Orbitrap MS has the similar analysis mode called parallel reaction monitoring (PRM). ${ }^{14,15}$ It is a targeting MS mode that performs the parallel acquisition of all transitions of the target peptides. This in combination with high selectivity in the quadrupole MS and high-resolution in the Orbitrap MS makes it a good method for targeted proteomics in complicate matrice. ${ }^{16}$ 
The PRM scanning mode has been applied in several studies, as for the monitoring of species-specific peptide biomarkers to authenticate fish and shellfish species ${ }^{17,18}$ and to quantify the indicated protein in human plasma or serum. ${ }^{19,20}$ However, to our knowledge, the applicability of PRM to the identification and detection of pork in meat mixture still has not been explored.

In current studies, we detected and identified proteotypic peptides of myosin by MS-based proteomic approach. Subsequently, PRM of Orbitrap MS with these peptides was adopted for authentication of pork in meat mixture. The performance of quantification with PRM for the pork proportion was investigated by prepared meat mixture.

\section{Materials and method}

\section{Chemicals}

Ammonium bicarbonate $\left(\mathrm{NH}_{4} \mathrm{HCO}_{3}\right)$, dithiothreitol (DTT), iodoacetamide (IA) and hydrochloric acid ( $\mathrm{HCl}, 37 \%)$ were obtained from Sigma-Aldrich (St. Louis, MO, USA). Acetonitrile (ACN) and formic acid (FA) were purchased from Merck (Darmstadt, Germany). All the reagents used were analytical or HPLC grade. Sequencing grade modified trypsin was from Shanghai Yaxin Biotechnology Co., Ltd (Shanghai, China). All chemical agents were prepared using ultrapure water and without further purification. Ultrapure water was obtained by a Milli-Q Gradient A10 water purification system (Millipore, Bedford, MA, USA) during all the experiments.

\section{Samples}

The commercial fresh meat (pork, chicken, sheep and beef) were purchased from local supermarket (TESCO, Hangzhou, China). Meat mixtures were prepared as follows. Raw pork meat was thoroughly mixed at weight percentage ratios of 1,5 and 50 with a mixture of equal weight (i.e. $1: 1: 1$ ) of raw beef, chicken and sheep meat (marked as $1 \%, 5 \%$ and $50 \%$ pork meat mixture).

\section{Bioinformatic analysis}

Protein sequences were obtained from the Universal Protein Resource (UniProt) databases. Protein alignment and sequence comparison were completed by Align tool of Uniprot. Regions of local similarity between sequences were performed by the Basic Local Alignment Search Tool (BLAST) of Uniprot. Protein identification was performed using Thermo Scientific Proteome Discoverer software 2.0 (Thermo Fisher Scientific, San Jose, CA, USA) and MaxQuant software (http://maxquant.org/, version 1.6.0.1). The whole workflow of pork authentication was shown in Fig. 1.

\section{Sample extraction and digestion}

Proteins were extracted from $5 \mathrm{~g}$ ground matrix in $15 \mathrm{~mL}$ Tris- $\mathrm{HCl}$ (200 mM, pH 9.2) by shaking for $30 \mathrm{~min}$. Then, the mixture was sonicated for $20 \mathrm{~min}$ at maximum intensity to improve the yield of protein dissolution. The tubs were centrifuged at $5000 \mathrm{~g}$ for $15 \mathrm{~min}$ to remove debris. The supernatant was heated at $120{ }^{\circ} \mathrm{C}$ for $10 \mathrm{~min}$. Subsequently, the $100 \mu \mathrm{L}$ supernatant, $100 \mu \mathrm{L} 500 \mathrm{mM}$

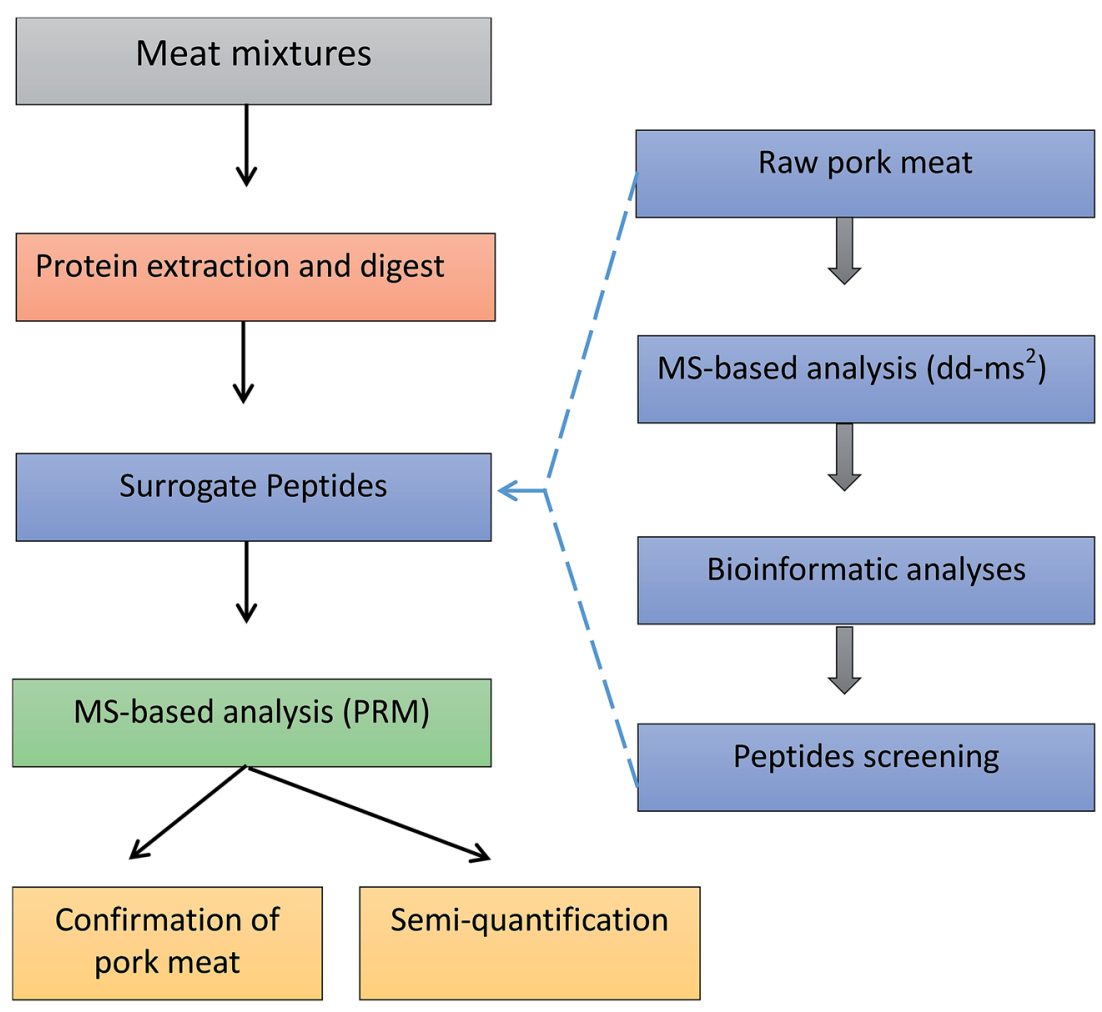

Fig. 1 The workflow of pork authentication in meat mixtures. 
$\mathrm{NH}_{4} \mathrm{HCO}_{3}$ and $665 \mu \mathrm{L}$ deionized water were mixed in an Eppendorf tube. $10 \mu \mathrm{L} 50 \mathrm{mM}$ DTT solution was added to the mixtures and reduced in $40{ }^{\circ} \mathrm{C}$ water bath for $30 \mathrm{~min}$ at this stage. In the next step an alkylation was performed by adding $10 \mu \mathrm{L}$ of $150 \mathrm{mM}$ IAA in the dark for $30 \mathrm{~min}$ at room temperature. Immediately prior to the incubation, $100 \mu \mathrm{L}$ of $500 \mathrm{mM} \mathrm{NH}_{4} \mathrm{HCO}_{3}$ and $10 \mu \mathrm{L}$ of $400 \mu \mathrm{g} \mathrm{mL}^{-1}$ trypsin (freshly prepared) were added and incubated $15 \mathrm{~h}$ at $40{ }^{\circ} \mathrm{C}$. The reaction was terminated by addition of $5 \mu \mathrm{L}$ formic acid. The insoluble substances in tryptic hydrolysates were removed by centrifuging at $13000 \mathrm{~g}$ for $10 \mathrm{~min}$. Before analysis, the solution was filtered through nylon filters, $0.22 \mu \mathrm{m} \times 13 \mathrm{~mm}$ (Agela technologies, New York, USA).

\section{Chromatographic conditions}

A Vanquish UHPLC system consisting of a quaternary pump, an autosampler and a column oven was used in this test (all Thermo Scientific, San Jose, CA, USA). Chromatographic separation was carried out on an Acquity UPLC BEH 300 C18 column $(1.7 \mu \mathrm{m}, 2.1 \mathrm{~mm} \times 100 \mathrm{~mm})$ maintained at $30{ }^{\circ} \mathrm{C}$. The $0.1 \% \mathrm{FA}$ aqueous solution (A) and $0.1 \%$ FA ACN solution (B) were used for the mobile phases. Gradient elution was: $3 \% \mathrm{~B}$ to $20 \% \mathrm{~B}$ for $2 \mathrm{~min} ; 20 \% \mathrm{~B}$ to $70 \%$ B for $14 \mathrm{~min}$; $70 \%$ B to $100 \%$ B for $1 \mathrm{~min}$; keeping $100 \%$ B for $1 \mathrm{~min}$; $100 \% \mathrm{~B}$ to $3 \% \mathrm{~B}$ for $0.5 \mathrm{~min}$; reequilibration at the initial conditions for $1.5 \mathrm{~min}$ for a total run time of $20 \mathrm{~min}$. The flow rate for separations was maintained at $0.3 \mathrm{~mL} \mathrm{~min}^{-1}$ and a $10.0 \mu \mathrm{L}$ injection volume was used for all standards and samples.

\section{MS conditions}

The UPLC system was coupled to a Q-Orbitrap-MS equipped with a heated electrospray ionization probe (HESI) operating in positive mode (Thermo Fisher Scientific). The following ionization parameters were applied: electrospray voltage $3.5 \mathrm{kV}$ for positive mode, capillary temperature $320{ }^{\circ} \mathrm{C}$, aux gas heater temp $350{ }^{\circ} \mathrm{C}$, sheath gas $\left(\mathrm{N}_{2}\right) 40$ arbitrary units (arb), auxiliary gas $\left(\mathrm{N}_{2}\right) 10$ (arb), and S-lens RF level at 50 (arb). The properties of full MS were: full mass resolution, 70 000; dd-MS ${ }^{2}$ resolution, 17 500; stepped NCE, 15, 28, 50; dd settings, charge exclusion, $4-8,>8$; peptide match preferred. The properties of PRM were: resolution, 70 000; NCE, 28. The precursor ions and fragment mass used in PRM were obtained by the analysis of full MS/dd$\mathrm{MS}^{2}$ data with Proteome Discoverer software. The instrument was calibrated in positive mode every 7 days using the Pierce LTQ Velos ESI positive-ion calibration solutions from manufacturer (containing caffeine, the tetrapeptide MRFA and a mixture of fluorinated phosphazines ultramark 1621).

\section{Results and discussion}

\section{Peptide mass fingerprinting}

The date dependent acquisition (DDA) of high resolution MS was adopted for collecting peptide mass fingerprinting (PMF) of pork muscle. As described by Kumar et al. ${ }^{\mathbf{2 1}}$ data dependent acquisition is a mode of data collection in tandem mass spectrometry in which a fixed number of peaks selected from a survey scan using predetermined rules, and the corresponding ions are subjected to $\mathrm{MS} / \mathrm{MS}$ analysis. In QOrbitrap, full MS/dd-MS ${ }^{2}$ performs data-dependent scans. Once the targeted compounds are detected, precursor ions that are selected by the quadrupole are sent to the HCD collision cell of the Orbitrap mass spectrometer. In order to get peptide information as much as possible, we set stepped normalized collision energy (NCE) for 15, 28, and 50. The mass spectrometry will perform a stepwise fragmentation on the precursor ion. All fragments created in the steps are collected and sent to the Orbitrap analyzer for one scan detection. In dd-MS ${ }^{2}$ setting, we set minimum AGC target $5.0 \times 10^{2}$ to obtain intensity threshold $1.0 \times 10^{4}$. This field displays the minimum intensity that a mass peak requires to initiate a data dependent scan. The low intensity threshold can record more information of fragments.

\section{Bioinformatic analysis}

Most of previous studies $\mathbf{9 , 1 0 , 2 2}^{\mathbf{2}}$ explored specific peptides from myoglobin (MB) for muscle authentication. Actually, myosin is also good resource for marker peptide. Myosin comprises a superfamily of ATP-dependent motor protein and is best known for their role in muscle contraction. It is one kind of abundant protein and is plentiful in red or white meat. Furthermore, myosin is relatively stable comparing with other sarcoplasmic proteins. ${ }^{23}$ Accordingly, we selected myosin proteins as the biomarkers for pork muscle. After analysis by Proteome Discoverer and MaxQuant software, main myosin proteins were found (Table 1). Both myosin-4 and myosin-1 owned high scores of Sequest HT (more than 200). Their coverage of peptides in proteins was not less than $30 \%$.

\section{Peptide screening}

Although 125 peptides for myosin- 4 and myosin- 1 were identified (Table 1), these peptides cannot be directly used for marker peptides. The screening criteria were: (1) unique or without similarity to related species; (2) easy detected with MS systems; (3) abundant in muscles; (4) reproducible (digestion). After the analysis by extracted ion chromatogram of peptides and BLAST tools, the targeted peptides were founded (Table 2). We selected five peptides (HKYEETQAELEASQK, KLETDISQIQGEMEDIVQEAR, LETDISQIQGEMEDIVQEAR, KLETDISQIQGEMEDIIQEAR and LETDISQIQGEMEDIIQEAR) as the potential surrogate peptides, which are not included in sheep, beef or chicken muscle (Table 2). For evaluating their heat stability, the digested sample of pork muscle was heated at $100{ }^{\circ} \mathrm{C}$ for different time. As shown in Fig. 2, mass responses of peptides were all weakened with the increase of heating time. Two peptides of KLETDISQIQGEMEDIVQEAR and HKYEETQAELEASQK can be adopted for authentication on heattreated meat because of their strong MS response after $2 \mathrm{~h}$ heating.

Other peptides of myosin were reported for pork detection by mass spectrometry. Bargen et al. used species-specific tryptic marker peptides (TLAFLFAER of myosin-4 and SALAHAVQSSR for myosin-4/-1) for detection of pork by QTrap 5500. ${ }^{3}$ Orduna et al. proposed peptide (TLAFLFTGAAGADAEAGGGK of myosin1) as the specific proteotypic peptide for pork muscle. ${ }^{10}$ But, in present study, these peptides were either not identified or had 
Table 1 Myosin from the searching of PMF

\begin{tabular}{llllllrr}
\hline Accession & Description & Coverage\% & Peptides & PSMs & AAs & MW [kDa $]$ & Score Sequest HT \\
\hline Q9TV62 & Myosin-4 & 41 & 70 & 75 & 1937 & 223.1 & 268.7 \\
Q9TV61 & Myosin-1 & 33 & 55 & 57 & 1939 & 223.0 & 205.4 \\
Q29069 & Myosin light & 49 & 6 & 7 & 150 & 16.7 & 26.0 \\
Q19AA7 & Myosin light chain & 48 & 7 & 8 & 169 & 18.9 & 24.6
\end{tabular}

Table 2 Myosin-derived marker peptides

\begin{tabular}{|c|c|c|c|c|c|c|}
\hline \multirow[t]{4}{*}{ Myosin-4 } & HKYEETQAELEASQK & Yes & - & & & \\
\hline & NLTEEMAGLDENIAK & Yes & & Yes & Yes & \\
\hline & LETDISQIQGEMEDIVQEAR & Yes & & & & Yes \\
\hline & IAEKDEEIDQMK & & Yes & & & \\
\hline Myosin-1 & KLETDISQIQGEMEDIIQEAR & & & & & Yes \\
\hline
\end{tabular}

low MS response, which may be caused by different sample preparation and instrumental conditions.

\section{Analysis by PRM}

As shown in Fig. 3, five surrogate peptides were well separated on BEH300 C18 column within $10 \mathrm{~min}$. All fragments of the targeted precursors are measured and the selection of fragments for quantification is done post-acquisition. The identification and quantification were operated with software of Thermo Xcalibur v4.0. The fragmentations of precursor ions were recorded based on b-type and y-type ions which came from cleavage between the nitrogen and carbonyl carbon (Table 3). The y-type and b-type ions can both lose a molecule of water (18 $\mathrm{Da})$ or ammonia $(17 \mathrm{Da})$ in secondary fragmentations. For example, fragments of HKYEETQAELEASQK contained 258.1416 $\left(\mathrm{y} 2-\mathrm{NH}_{3}\right), 986.4780\left(\mathrm{y} 9-\mathrm{NH}_{3}\right), 544.2726\left(\mathrm{y} 5-\mathrm{H}_{2} \mathrm{O}\right)$, and

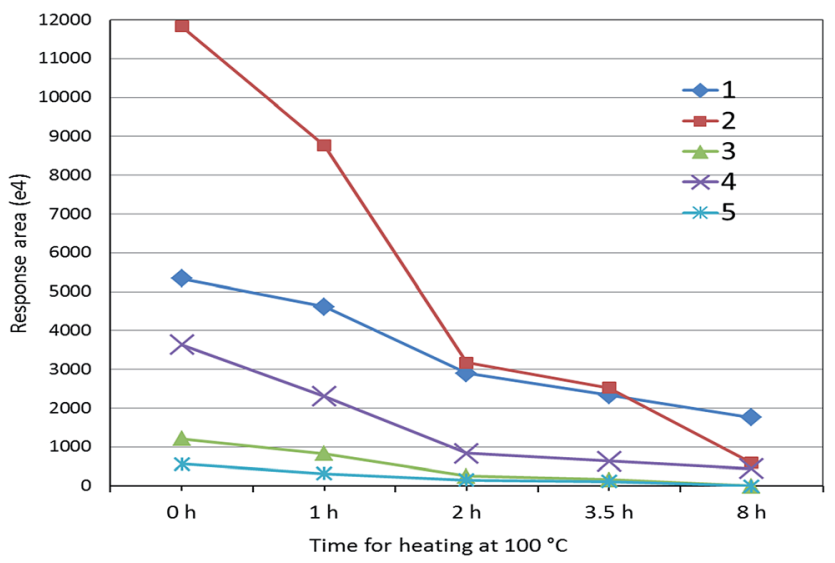

Fig. 2 The response of peptides to heating at $100{ }^{\circ} \mathrm{C}$ for different times ((1) HKYEETQAELEASQK; (2) KLETDISQIQGEMEDIVQEAR; (3) LETDISQIQGEMEDIVQEAR; (4) KLETDISQIQGEMEDIIQEAR; LETDISQIQGEMEDIIQEAR). etc. In addition, the b-type ions can lose a molecule of carbon monoxide (28 Da) to give rise to a-type ions.

In order to explore the linear correlation, pure raw pork muscles $(0.5 \mathrm{~g}, 1 \mathrm{~g}, 2 \mathrm{~g}, 3 \mathrm{~g}$, and $5 \mathrm{~g}$ ) were adopted for obtaining surrogate peptides and analyzed by PRM. A linear regression analysis was calculated by proteotypic peptide peak areas $(y)$ and weights of pork muscles $(x)$. The correlation coefficient $R^{2}$ of five surrogate peptides were all more than 0.9 (Table 3 ). The limit of detection (LOD) was determined on response at a signal-to-noise ratio $(\mathrm{S} / \mathrm{N})$ of 3 . When the most sensitive peptide (KLETDISQIQGEMEDIVQEAR) was used, the LOD can be up to $0.005 \mathrm{~g}$ pork muscle.

The analyses of the peptides used as surrogates for proteins are commonly performed in mode of SRM or MRM on triple quadrupole mass spectrometers. ${ }^{24}$ In such experiments, predefined series of transitions (precursor/fragment) are sequentially measured for precise quantification. Although it can complete precise quantification over a wide dynamic range, the low resolution of both Q1 and Q3 mass analyzers can result in interfering signals from complicate matrix. ${ }^{11,25,26}$ PRM uses tandem MS to simultaneously monitor fragment ions of the targeted peptide with high resolution and mass accuracy. ${ }^{27}$ The selected precursor ion is isolated by the quadrupole and fragmented in the high-energy collisional dissociation (HCD) cell. The product ions are then monitored by an Orbitrap mass analyzer. ${ }^{27}$ Due to the parallel monitoring, selection of target peptide transitions do not need to be made in advance. Furthermore, PRM offers higher specificity than SRM on QqQ instruments, because it monitors product ions with high resolution, which is less likely to be affected by interfering ions.

\section{Method optimization and validation}

Analytical methods based on peptides strategies rely on the protein extraction and digestion. In extraction step, we adopted sonication to assist the protein dissolution. The extraction 


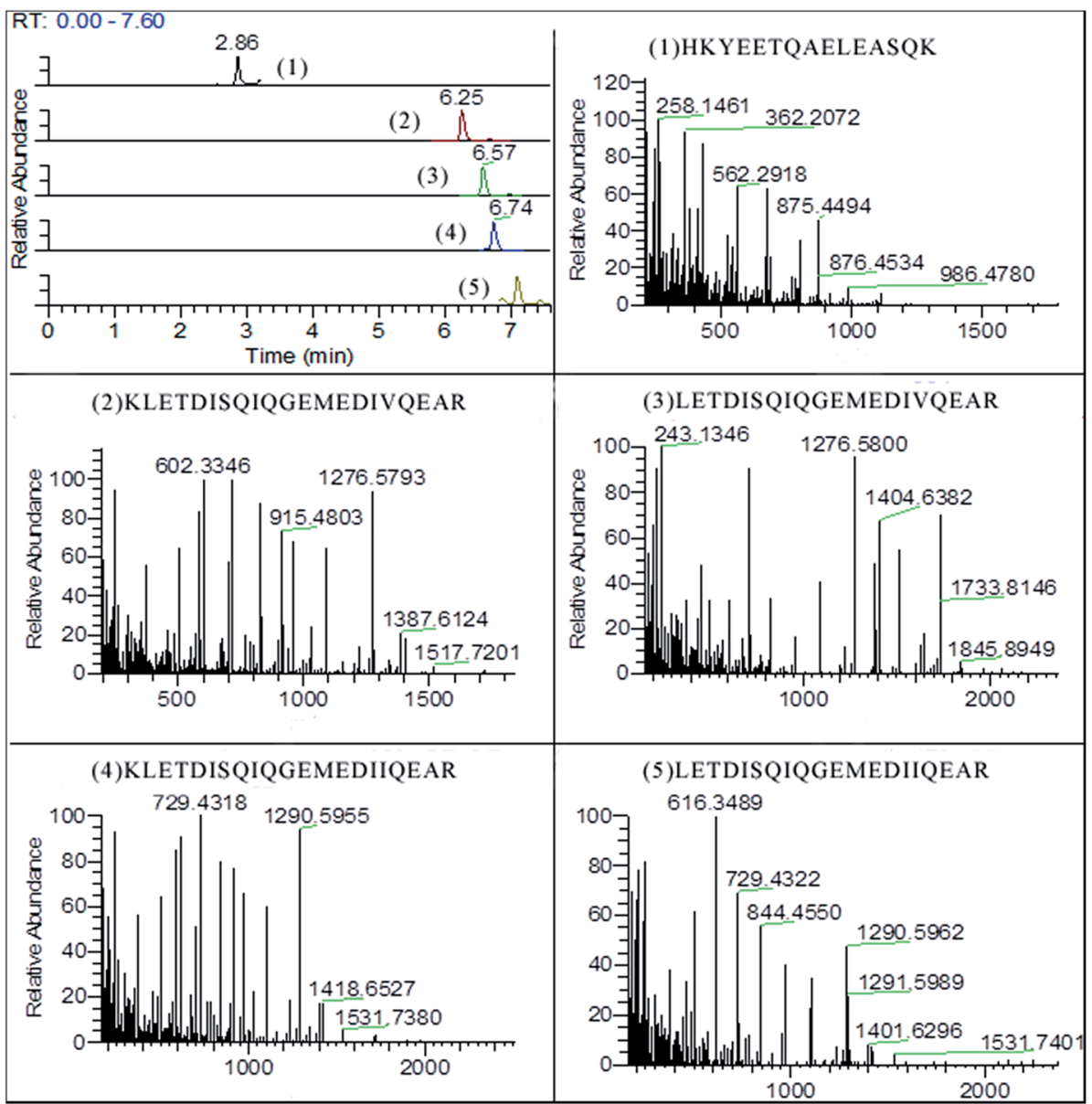

Fig. 3 The chromatogram of surrogated peptides and their mass spectra of fragments (5\% pork meat mixture).

Table 3 Surrogate peptides used for PRM analysis

\begin{tabular}{lllll}
\hline Peptide & Precursor $m / z$ (charge) & Main fragments $m / z$ & RT (min) & Coefficient $R^{2}$ \\
\hline HKYEETQAELEASQK & $597.6234^{(3+)}$ & $362.2072 / 433.2473 / 562.2918 / 875.4494$ & 2.86 \\
KLETDISQIQGEMEDIVQEAR & $811.4039^{(3+)}$ & $363.2219 / 602.3346 / 715.4158 / 1276.5798$ & 6.25 & 0.989 \\
LETDISQIQGEMEDIVQEAR & $1152.5548^{(2+)}$ & $715.4162 / 830.4415 / 1090.5161 / 1276.5800$ & 6.57 & 0.993 \\
KLETDISQIQGEMEDIIQEAR & $816.0758^{(3+)}$ & $503.2656 / 616.3488 / 729.4318 / 1290.5955$ & 6.74 & 0.905 \\
LETDISQIQGEMEDIIQEAR & $773.3775^{(3+)}$ & $503.2666 / 616.3499 / 729.4322 / 844.4550$ & 7.09 & 0.967
\end{tabular}

solutions were then heated at high temperature of $120{ }^{\circ} \mathrm{C}$ in order to inactive protein functions and kill potential microbes. Commonly, targeted proteins for quantification need to be separated by precipitation and SDS-PAGE. This is time consuming and may not be appropriate for rapid analysis of suspecting meat samples. We directly digested the protein in solution without protein purification. A higher temperature (40 ${ }^{\circ} \mathrm{C}$ ) was used for protein digestion. All of above procedures were applied in order to improve yield and reproducibility of surrogate peptides.

Peptides-based MS method can perform semi-quantitative and quantitative analysis. For evaluation quantitative results, we prepared meat mixtures of pork meat with beef, chicken and sheep. Meat mixtures (containing pork meat $1 \%, 5 \%$ and $50 \%$ ) were quantified by the calibration of surrogate peptide peak areas $(y)$ and weights of raw pork muscles $(x)$. The RSD values $(n=5)$ of $1 \%, 5 \%$ and $50 \%$ mixed meat between detected and designated values were $13.8 \%, 8.5 \%$ and $4.6 \%$. The $\mathrm{S} / \mathrm{N}$ of $1 \%$ mixed meat $(n=5)$ was $6-15 \%$, and for $5 \%$ mixed meat $(n=5)$ was $30-56 \%$. The relative LOD of this method was $0.5 \%$ mixed meat. Actually, studies have indicated that PRM on Q-Exactive instruments and MRM on QqQ MS have comparable analytical sensitivities, dynamic ranges, and precision for protein quantitation. ${ }^{26,28}$ The quantification relies on spiked stableisotope labeled internal standard (SIS) protein or peptides. However, SIS proteins or peptides were not obtained in present study because of its high cost. We used the raw pork muscles as the external standards for calibrating. 


\section{Conclusion}

Following the identification and screening of surrogate peptides, we have developed a sensitive and rapid PRM method based on high resolution Orbitrap MS for pork detection. Using the PRM of targeted precursor for surrogate peptide, the LOD in mixed meat can achieve up to $0.5 \%$. Although the stable-isotope labeled internal standard (SIS) protein or peptides were not obtained, quantitation can be performed using the raw pork muscle as the external standard. The present method can be applied for routine analysis of pork in meat mixtures.

\section{Author contributions statement}

X.-D. P., J. C., Q. C. and B.-F. H. conceived the experiment(s), X.-D. P., and J. C., conducted the experiment(s), X.-D. P., J.-L. H. and B.-F. H. analyzed the results. All authors reviewed the manuscript.

\section{Conflicts of interest}

The authors declare no competing financial interests.

\section{Acknowledgements}

The authors are thankful to M. L. Wang, J. S. Zhang and Z. X. Cai for the help on the experiment.

\section{References}

1 G. P. Danezis, A. S. Tsagkaris, F. Camin, V. Brusic and C. A. Georgiou, TrAC, Trends Anal. Chem., 2016, 85, 123-132.

2 A. Vlachos, I. S. Arvanitoyannis and P. Tserkezou, Crit. Rev. Food Sci. Nutr., 2016, 56, 1061-1096.

3 C. von Bargen, J. Brockmeyer and H. U. Humpf, J. Agric. Food Chem., 2014, 62, 9428-9435.

4 M. A. Sentandreu and E. Sentandreu, Food Res. Int., 2014, 60, 19-29.

5 I. Ortea, G. O'Connor and A. Maquet, J. Proteomics, 2016, 147, 212-225.

6 S. A. Drivelos and C. A. Georgiou, TrAC, Trends Anal. Chem., 2012, 40, 38-51.

7 S. A. Lim and M. U. Ahmed, Food Chem., 2016, 206, 197-203. 8 Q. Chen, X. D. Pan and B. F. Huang, RSC Adv., 2017, 7, 3290332908.
9 A. D. Watson, Y. Gunning, N. M. Rigby, M. Philo and E. K. Kemsley, Anal. Chem., 2015, 87, 10315-10322.

10 A. R. Orduna, E. Husby, C. T. Yang, D. Ghosh and F. Beaudry, Food Addit. Contam., Part A, 2015, 32, 1709-1717.

11 S. A. Sarah, W. N. Faradalila, M. S. Salwani, I. Amin, S. A. Karsani and A. Q. Sazili, Food Chem., 2016, 199, 157164.

12 A. J. Claydon, H. H. Grundy, A. J. Charlton and M. R. Romero, Food Addit. Contam., Part A, 2015, 32, 1718-1729.

13 D. Ohana, H. Dalebout, R. J. Marissen, T. Wulff, J. Bergquist, A. M. Deelder and M. Palmblad, Food Chem., 2016, 203, 2834.

14 A. C. Peterson, J. D. Russell, D. J. Bailey, M. S. Westphall and J. J. Coon, Mol. Cell. Proteomics, 2012, 11, 1475-1488.

15 A. Bourmaud, S. Gallien and B. Domon, Proteomics, 2016, 16, 2146-2159.

16 H. Li, J. Han, J. Pan, T. Liu, C. E. Parker and C. H. Borchers, J. Mass Spectrom., 2017, 52, 319-341.

17 M. Carrera, B. Canas, D. Lopez-Ferrer, C. Pineiro, J. Vazquez and J. M. Gallardo, Anal. Chem., 2011, 83, 5688-5695.

18 I. Ortea, B. Canas and J. M. Gallardo, J. Chromatogr. A, 2011, 1218, 4445-4451.

19 M. Sundberg, E. M. Strage, J. Bergquist, B. S. Holst and M. Ramstrom, PLoS One, 2016, 11, e0167138.

20 Z. Huang and X. D. Pan, RSC Adv., 2017, 7, 20212-20218.

21 P. Kumar, A. Rubies, F. Centrich, M. Granados, N. CortesFrancisco, J. Caixach and R. Companyo, Anal. Chim. Acta, 2013, 780, 65-73.

22 B. Prandi, F. Lambertini, A. Faccini, M. Suman, A. Leporati, T. Tedeschi and S. Sforza, Food Control, 2017, 74, 61-69.

23 E. Tornberg, Meat Sci., 2005, 70, 493-508.

24 V. Vidova and Z. Spacil, Anal. Chim. Acta, 2017, 964, 7-23.

25 Q. Chen, X. D. Pan, B. F. Huang and J. L. Han, J. Pharm. Biomed. Anal., 2017, 145, 525-530.

26 G. E. Ronsein, N. Pamir, P. D. von Haller, D. S. Kim, M. N. Oda, G. P. Jarvik, T. Vaisar and J. W. Heinecke, J. Proteomics, 2015, 113, 388-399.

27 Q. Y. Liu, J. L. Liu, C. D. Ren, W. T. Cai, Q. Q. Wei, Y. Song and J. Yu, Int. J. Nanomed., 2017, 12, 1663-1671.

28 C. Schiffmann, R. Hansen, S. Baumann, A. Kublik, P. H. Nielsen, L. Adrian, M. von Bergen, N. Jehmlich and J. Seifert, Anal. Bioanal. Chem., 2014, 406, 283-291. 